\title{
EDITORIAL
}

\section{El papel de las organizaciones no gubernamentales en la lucha antitabáquica. El Consejo Mexicano contra el Tabaquismo}

E n este número monográfico de la revista del Instituto Nacional de Salud Pública se presenta información amplia y detallada sobre la situación actual del tabaquismo en el ámbito internacional, pero sobre todo en México. El efecto negativo relacionado con el tabaquismo está comprobado cient ficamente y la evidencia de sus graves consecuencias es cada vez más abundante.

El tabaquismo es la causa más importante y a la vez más evitable de morbilidad, incapacidad y muerte en muchos pa ses. Causa 20\% de todas las muertes, 30\% de todos los casos de cáncer y $90 \%$ de los casos de cáncer de pulmón.

La mortalidad anual secundaria al tabaquismo se incrementará de 3 millones en 1995 a 10 millones en 2025 , sobre todo como resultado de la mortalidad en los pa ses en desarrollo, en donde el número de muertes aumentará de 1 millón en 1995 a 7 millones en 2025 como resultado del escaso control del tabaquismo. ${ }^{1}$

Cerca de $10 \%$ de las muertes derivadas del tabaquismo se presenta en fumadores pasivos por causas semejantes a las de los fumadores activos. El efecto en el fumador pasivo no sólo es crónico, como en el caso del cáncer; de manera aguda hay alteraciones cardiovasculares importantes, como aumento en la concentración sangu nea de monóxido de carbono y reducción en el flujo de las arterias coronarias. ${ }^{2}$ En México la protección del no fumador y la garant a de espacios libres de humo de tabaco sólo existe en teor a.

Las encuestas nacionales muestran una reducción en la edad de inicio del tabaquismo: en 1988 se ubicaba entre los 18 y 25 años de edad; diez años después se redujo a 11 y 14 años de edad. Esto resulta preocupante no sólo porque el joven desarrolla adicción a la nicotina más rápido sino también porque cuanto menor es la edad de exposición al humo del tabaco, tanto mayor es el riesgo de daño del $\mathrm{ADN},{ }^{3}$ a tal grado que un producto en gestación de madre no fumadora tiene mayor riesgo de desarrollar cáncer durante la infancia si el padre fumó durante el embarazo. ${ }^{4}$ Asimismo, se ha demostrado que ciertas áreas del sistema nervioso central afectadas con el est mulo de recompensa no maduran hasta después de los 18 años; en consecuencia, el consumo de tabaco en edades tempranas incrementa el riesgo de consumir otras drogas, lo que favorece el proceso de adicción más rápida e intensamente. ${ }^{5,6}$ Con estas evidencias, la recomendación es evitar o retrasar lo más posible el contacto de los jóvenes con el tabaco, al que se considera una "droga puerta de entrada" a otras adicciones. La mayor a de los fumadores adolescentes muestra signos de dependencia antes de alcanzar la edad legal para votar, manejar o comprar alcohol.

En los jóvenes fumar un solo cigarrillo puede provocar s ndrome de abstinencia, como lo ilustra el caso del recién fallecido Allen Carr, incansable luchador contra el tabaquismo y autor del libro La manera fácil de dejar de fumar. Carr relata que a los 18 años, cuando fumó su primer cigarrillo, le resultó tan desagradable que se preguntó qué estaba haciendo, pero al terminar ya quer a otro. ${ }^{7} \mathrm{El}$ efecto del tabaquismo en la esperanza de vida y salud de la población es enorme. Quien se inicia a temprana edad y continúa fumando a lo largo de su vida tiene 50\% de probabilidades de fallecer a consecuencia de ese hábito. Sin embargo, nunca es tarde para dejar de fumar.

El riesgo de desarrollar cáncer de pulmón es menor a $2 \%$ en quienes dejan de fumar antes de los 30 años y de $16 \%$ para quienes siguen fumando durante toda la vida. Sin embargo, dejar de fumar a los 60 años de edad reduce el riesgo a 10\%, ${ }^{8}$ y quienes ya tienen cáncer gozarán de un mejor pronóstico si se abstienen de hacerlo. ${ }^{9,10}$ En cuanto a enfermedad pulmonar obstructiva crónica (EPOC), en quienes dejan de fumar a los 50 años de edad, el volumen de la espiración forzada en un segundo $\left(\mathrm{VEF}_{1}\right)$ se reduce a $28 \%$ al cumplir 85 años respecto del riesgo que ten an a los 25 años de edad; en los no fumadores la reducción puede 
ser superior a 75\%; sin embargo, en quienes continuaron fumando después de cumplir 50 años se reduce a $8 \%$ a los 75 años de edad. ${ }^{11}$

\section{Políticas recientes en México contra el tabaco}

A pesar de este perturbador escenario, hasta ahora en México la creación y aplicación de pol ticas públicas destinadas a disminuir el consumo de tabaco y a proteger a los no fumadores han tenido un efecto limitado. La ley no ha sido respetada aun cuando el marco regulatorio establece prohibiciones a la venta de tabaco a menores de edad y ventas unitarias de cigarros, restricciones a la publicidad y patrocinio de productos de tabaco y prohibición a fumar en edificios de la administración pública propiedad del gobierno federal (oficinas o dependencias y aquéllos en los que se prestan servicios).

Por otro lado, en años recientes se han dado avances en materia fiscal, pero aún resultan insuficientes para disminuir el consumo de tabaco. El Impuesto Especial de Producción y Servicios (IEPS) aumentó de una tasa de $100 \%$ en 2000 a $140 \%$ en 2007 . De acuerdo con la Organización Mundial de la Salud (OMS), para que esta medida tenga un efecto verdadero, el impuesto a los cigarrillos debe representar una proporción de entre dos tercios y tres cuartos del precio del producto.

Uno de los aciertos de la pol tica antitabáquica es el aumento considerable en el número de cl nicas de tratamiento del tabaquismo en todo el pa s. En 2000 los Servicios Estatales de Salud contaban con sólo 32 cl nicas, mientras que para 2006 el número de cl nicas privadas y públicas aumentó a 200. Dichas cl nicas y el esfuerzo individual de médicos y trabajadores de la salud, apoyados en tratamientos antitabáquicos y nuevos fármacos que reducen el s ndrome de abstinencia a la nicotina, han contribuido a aumentar el número de ex fumadores. Aunque estos resultados son de gran importancia, aún representan un esfuerzo pequeño comparado con el que se necesita para reducir de manera significativa los ndices de tabaquismo y, sobre todo, para proteger a los no fumadores mediante el establecimiento de espacios libres de humo.

\section{El Consejo Mexicano Contra el Tabaquismo}

Con la intención de incrementar la eficacia de la lucha antitabáquica, en fechas recientes se creó el Consejo Mexicano Contra el Tabaquismo (CMCT). El CMCT es una organización no gubernamental (ONG) que surge de la colaboración de un grupo multidisciplinario de profesionales de la salud, académicos, investigadores, estadist grafos, asesores legales, publicistas y empresarios preocupados por los riesgos vinculados al tabaquismo.

El CMCT es una organización que aprovecha los resultados y experiencia de sus miembros, quienes se han destacado por su labor y experiencia en instituciones de prestigio, como el Instituto Nacional de Cancerolog a, el Instituto Nacional de Salud Pública, el Instituto Nacional de Enfermedades Respiratorias, el Instituto de Investigaciones Jur dicas y la Facultad de Medicina de la Universidad Nacional Autónoma de México (UNAM), la Fundación Mexicana para la Salud y la consultora de estudios demoscópicos Parametr a. Con base en un vasto conocimiento multidisciplinario, se pretende impulsar la investigación y la difusión de información que contribuya al diseño y ejecución de mejores pol ticas públicas para disminuir la incidencia del consumo del tabaco.

Los pa ses que han tenido éxito en reducir los ndices de tabaquismo lograron conjugar pol ticas frontales de combate al tabaquismo con la creación de organismos especializados en la materia, con lo que consiguieron catalizar la participación de la sociedad civil en el impulso de estrategias integrales para disminuir la incidencia y mortalidad. Tal es el caso de Canadá, mediante el Consejo Canadiense para el Control del Tabaco, Irlanda, con la Oficina de Control de Tabaco, y España, con el Comité Nacional de Prevención del Tabaquismo. ${ }^{12}$

Los avances significativos en materia de control del tabaco en esos pa ses se deben en gran medida a los esfuerzos coordinados entre el gobierno y la sociedad civil. Juntos lograron impulsar pol ticas públicas frontales contra el tabaquismo, campañas de prevención y restricciones para fumar en lugares públicos, lo que provocó un cambio importante en la conducta de los fumadores.

A partir de los antecedentes antes mencionados, el CMCT pretende formar una sociedad consciente y comprometida contra el tabaquismo, para lo cual busca fortalecer y difundir información cient fica, as como promover la adecuación del marco jur dico mexicano para que garantice espacios libres de humo y la atención médica necesaria para combatir esta enfermedad. En México las autoridades están conscientes de que la lucha antitabáquica representa grandes dificultades y enormes complejidades, pero también están convencidas del indudable efecto positivo que ese esfuerzo tendrá en el largo plazo. Para lograrlo, el CMCT considera las siguientes prioridades:

- Desarrollar y difundir información cient fica sobre el tabaquismo.

- Ampliar y hacer respetar los espacios libres de humo. 
- Desarrollar campañas de prevención novedosas y efectivas.

- Promover el acceso a tratamientos para tabaquismo de alta calidad.

- Desarrollar y promover campañas de prevención y protocolos de atención espec ficos para jóvenes.

- Promover la formación de recursos humanos en el área de la salud, capacitándolos para el tratamiento del tabaquismo en todos los pacientes.

En una primera etapa, el CMCT ofrecerá en su portal de Internet tanto información cient fica relacionada con el tabaco y sus riesgos como información sobre la legislación relevante, apoyo y consejo a quienes deseen dejar de fumar y alternativas para combatir la adicción. También proporcionará información sobre las ventajas de trabajar en espacios cien por ciento libres de humo y los mecanismos necesarios para que las empresas se certifiquen.

En la actualidad el CMCT desarrolla un proyecto que consiste en generar y aplicar una encuesta de opinión pública sobre espacios libres de humo y la percepción social sobre la publicidad del tabaco. La recolección y difusión de esa información será de gran utilidad para que legisladores y actores sociales clave redacten leyes y ejecuten acciones contra el tabaquismo. El CMCT brindará la información y asesor a que el gobierno, legisladores, empresas y público general le soliciten sobre los beneficios de no fumar, la importancia de garantizar espacios libres de humo, el acceso a tratamientos para dejar de fumar, entre otros temas, siempre basado en información cient fica sólida.

Otra actividad prevista por el CMCT es realizar un estudio comparado de legislación internacional dirigida a garantizar y ampliar espacios libres de humo. A partir de los resultados de ese análisis, realizará una propuesta concreta para México. Este proyecto será de gran relevancia porque estará asesorado por juristas expertos en la materia. También considera realizar un segundo estudio prospectivo sobre el derecho de los trabajadores a laborar en ambientes cien por ciento libres de humo.

El crecimiento en la mortalidad secundaria al tabaquismo en todos los sectores de la población demuestra que la batalla contra el tabaquismo aún está por ganarse. La integración de expertos y la sinergia interinstitucional que se reúnen en el CMCT permitirá diseñar, desarrollar y difundir materiales y campañas novedosas enfocadas a reducir efectivamente la prevalencia del consumo de tabaco.

Asimismo, se lanzará una serie de actividades de publicidad antitabaco diseñadas para informar a la sociedad, en especial a los jóvenes, sobre los efectos negativos del tabaquismo en la salud, la necesidad de respetar y ampliar los ambientes libres de humo y la legislación vigente relativa a control del tabaco. Los mensajes serán diseñados de manera que penetren en la población y provoquen una reacción tanto en fumadores como en no fumadores. Se pretende transmitir recomendaciones que no sean percibidas sólo como sermones correctivos contra los fumadores.

La lucha antitabáquica representa grandes dificultades y enormes complejidades. En ella se confronta a poderosos intereses y patrones de conducta arraigados. Quien defiende su derecho a un espacio libre de humo es criticado y acusado de intolerante y descortés. Se han confundido los verdaderos y leg timos derechos humanos. La protección al no fumador no debe ser catalogada como una concesión arbitraria sino como una leg tima defensa a la salud.

Un argumento defensivo que con frecuencia se escucha entre los fumadores es el siguiente: "fumar me gusta, soy libre de hacerlo y nadie tiene por qué coartar $\mathrm{mi}$ libertad". Es indiscutible que el fumador experimenta un placer al fumar, pero dicho placer consiste en disminuir el s ndrome de abstinencia a la nicotina, que es una sustancia mucho más adictiva que el alcohol, la marihuana y la coca na. ${ }^{13}$ La búsqueda de ese placer es distinta de la búsqueda de muchos otros placeres de la vida diaria, ya que afecta la salud de terceros. El adicto no es libre sino esclavo del s ndrome de abstinencia, y en ocasiones es incapaz de respetar ciertos principios y buenos propósitos. Con frecuencia el adicto no controla su conducta: en Inglaterra, 24\% de los actos de violencia es cometido por personas que consumen alcohol y $34 \%$ por individuos con otras adicciones, mientras que $8 \%$ se atribuye a pacientes esquizofrénicos. ${ }^{14}$

Es necesario entender la confusión en que viven grandes sectores de la población. Por un lado, reciben información sobre los daños provocados por el tabaquismo, pero a la vez saben que está permitido por la ley. Es común que en fiestas y actos sociales especiales se celebre con un puro. Este siniestro simulador con frecuencia goza de más privilegios que una delicadeza gastronómica o un vino fino. Resulta una iron a celebrar un cumpleaños o el inicio de una vida matrimonial con el instrumento responsable del mayor número de muertes.

El CMCT está comprometido a tratar de liberar de esta adicción a $27 \%$ de la población afectada y a proteger a $73 \%$ restante. Por ello, informará a fumadores y trabajadores las alternativas de apoyo para dejar de fumar e impulsará el respeto y la ampliación de espacios libres de humo (sustentado en la evidencia cient fica de los efectos negativos del humo secundario).

La lucha antitabáquica no es nueva. La historia muestra antecedentes de cientos de años sobre la nocivi- 
dad del tabaquismo y las acciones punitivas para tratar de evitarlo. Fumar o no fumar representa la decisión más importante en materia de salud que puede tomar un ser humano; por desgracia, la mayor a de los fumadores toma esa decisión durante la adolescencia.

El CMCT desea crear conciencia en la sociedad sobre la importancia que tiene la acción de fumar o abstenerse de ello. Probar un cigarrillo no representa una ingenua curiosidad; significa un riesgo potencialmente fatal y la exposición al humo secundario no es trivial. Por ello, el CMCT tiene como misión promover un cambio radical en la actitud social y pública hacia el cigarrillo, incrementar el número de personas decididas a abandonar el tabaco y proteger a los fumadores pasivos.

Juan W. Zinser*

\section{Referencias}

I. Peto R, et al. Mortality from smoking in developed countries 1950-2000. Second edition. Oxford: Oxford University, 2006.

2. Otsuka R, Watanabe $H$, Hirata K, Tokai K, et al. Acute effects of passive smoking on the coronary circulation in healthy young adults. JAMA 200I;286:436-44I.
3.Wiencke K, Thurston SW, Kelsey KT,Wain JC, et al. Early age at smoking initiation and tobacco carcinogen DNA damage in the lung.J Natl Cancer Inst 1999;91(7):614-619.

4. Ji BT, Shu XO, Linet MS, Zhang W, Wacholder S, Gao YT, et al. Paternal cigarette smoking and the risk of childhood cancer among offspring of nonsmoking mothers.J Natl Cancer Inst 1997;89:238-243.

5. Vega et al. Revisiting drug progression, long-range effects of early tobacco use.Addiction 2005; 100: I358-1369.

6. Zickler et al. Nicotine's multiple effects on the brains reward system drive addiction. NIDA notes 2003;17(6): I-3.

7.Allen Carr.Allen Carr's easy way to stop smoking. Paperback. 8. Peto R, Dorby S, Deo H, Silcocks P,Whitley E, Doll R, et al. Smoking, smoking cessation, and lung cancer in the UK since 1950: combination of national statistics with two case-control studies. BMJ 2000;321:323-329.

9.Videtic et al. Continued Cigarette Smoking by Patients Receiving Concurrent Chemoradiotherapy for Limited-Stage Small-Cell Lung Cancer Is Associated With Decreased Survival. JCO 2003;2I (8): I5441549.

10. William et al. Smoking and alcohol use may be risk factors for poorer outcome in patients with clear cell renal carcinoma. Urology 2000;55:31-35. II. Srivastava P, Curiee GP, Britton J. ABC of chronic obstructive pulmonary disease: Smoking cessation. BMJ 2006;332:1324-1326.

12. Consejo Canadiense para el Control del Tabaco (http://www.cctc.ca), Oficina de Control de Tabaco (http://www.otc.ie/) y Comité Nacional de Prevención del Tabaquismo (http://www.cnpt.es/).

13. Bergen AW, Caporaso N. Cigarette smoking.JNCI 1999;91:1365- 1375. 14.Walsh E, Fah T. Violence in society. BMJ 2002;325:507-508.

\footnotetext{
* Consejo Mexicano contra el Tabaquismo. México.
} 